\title{
Fixation of Biological Specimens by High Hydrostatic
}

\section{Pressure}

\author{
Genzou Takemura ${ }^{1,2}$, Hisayoshi Fujiwara ${ }^{1}$, Juntatsu OGawa ${ }^{1}$, Takako Fujiwara ${ }^{3}$ and \\ Shigetake SASAYAMA ${ }^{1}$
}

Department of Internal Medicine ${ }^{1}$, Kyoto University School of Medicine, Kyoto; Department of Internal Medicine ${ }^{2}$, Hyogo Prefectural Amagasaki Hospital, Hyogo; and Kyoto Women's University ${ }^{3}$, Kyoto, Japan

Received May 20, 1993

\begin{abstract}
Summary. We investigated whether or not high hydrostatic pressure could be used as a new method of histological fixation. Various high hydrostatic pressures from 200 to $800 \mathrm{MPa}$ (Mega Pascal) were applied to fresh organs including heart, liver, intestine and kidney of mice, and the gross and light microscopic findings were compared with those of organs fixed with formalin and those without fixation. The specimens processed with pressure were firm, elastic and pale, somewhat resembling the formalin fixed ones.

Light microscopic examination revealed well preserved fine structures in the heart and intestine subjected to approximately $450 \mathrm{MPa}$ for $15 \mathrm{~min}$ at room temperature, although the fine structures of the liver and kidney were not well preserved. The enzyme activity of alkaline phosphatase was rarely preserved in the formalinfixed kidney, but could be easily detected in kidneys processed with a pressure of $450 \mathrm{MPa}$. We conclude that high hydrostatic pressure can be used as a fixative, both for preserving the basic tissue structure in certain organs and for retaining the biological activity of an enzyme. In addition, the fixation is uniform, the processing is fast, and the materials can be handled safely. At present, however, its application is limited to specific organs.
\end{abstract}

High hydrostatic pressure can produce the protein denaturation (BRIDGMAN, 1914; JOHNSON et al., 1954; HEREMANS, 1982) that is the essential basis for the fixation of biological specimens (BAKER, 1958). However, hydrostatic pressure has never been used for histological fixation. This short report presents our investigation of whether or not high hydrostatic pressure could be used as a new method of fixation for the morphological examination of biological specimens.

\section{MATERIALS AND METHODS}

\section{High pressure apparatus and its manipulation}

The left panel of Figure 1 is a photograph of the apparatus used in this study, and the right panel shows its schematic layout. The high pressure chamber (obliquely lined area) in the compression apparatus (A) was filled with a physiological saline. The biological specimens were placed in the chamber, and compressed by piston (B). The vessel was linked to an oilpress cylinder (E), allowing the specimen to be hydrostatically compressed up to $800 \mathrm{MPa}$. The pressure was increased manually to the designed level by the oil-press apparatus (F). After compression for a set interval, the pressure of the chamber was instantly returned to atmospheric pressure by opening the pressure valve. The specimens were then removed from the chamber, and processed for histological observation.

\section{Experimental design}

Fresh postmortem hearts, livers, intestines and kidneys from BALB/c mice were handled in one of three ways to give a high hydrostatic pressure-treated group, a formalin-fixed group and a group without fixation.

For fixation by high hydrostatic pressure, the organs were placed in a high pressure chamber filled with a physiological saline, and subjected to pressures of various degrees (from 200 to 800 Mega Pascal (MPa) $=$ approx. 2,000 to 8,000 atm) for different times $(5,10$, 15,30 , and $60 \mathrm{~min}$ ).

Organs were fixed with $10 \%$ buffered formalin solution for $24 \mathrm{~h}$ under atmospheric pressure to produce the formalin-fixed controls.

Other parts of each organ, with neither formalin 

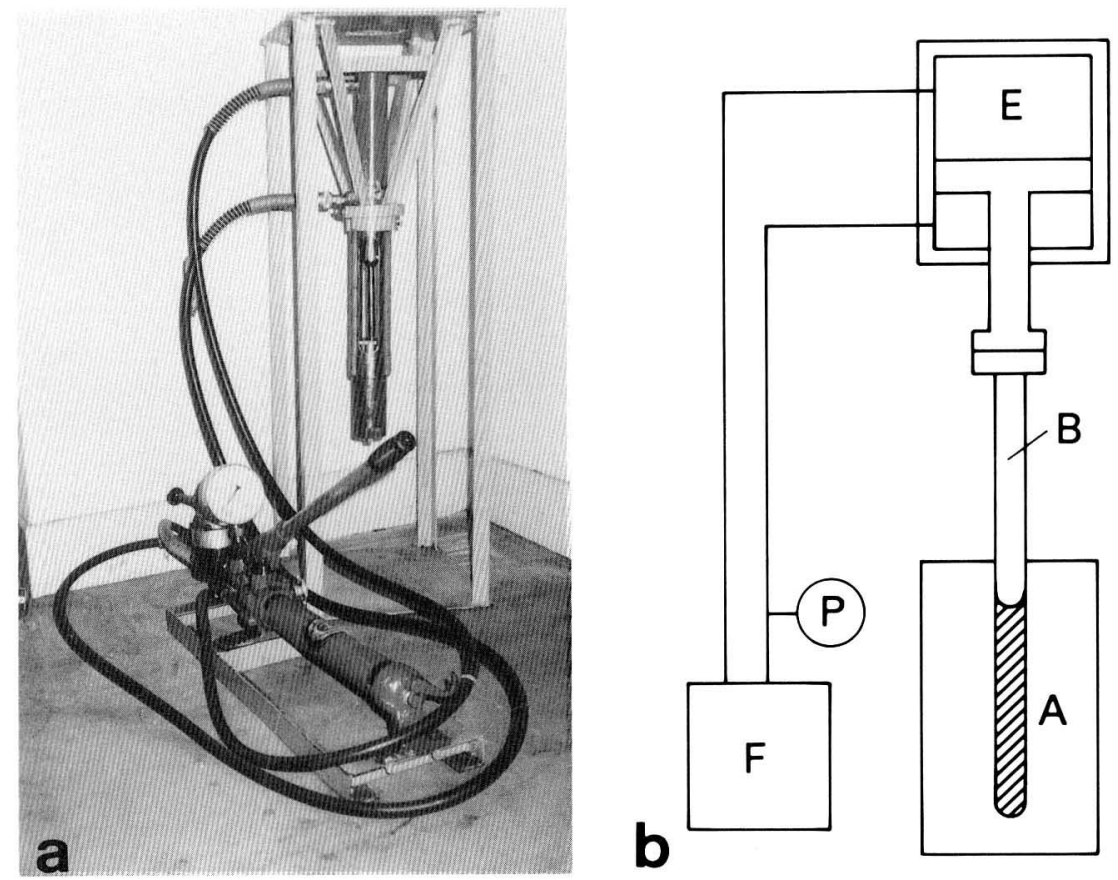

Fig. 1. Photograph of the high pressure apparatus (a) and its schematic layout (b). $A$ compression apparatus, $B$ piston, $E$ oil-press cylinder, $F$ oil-press apparatus, $P$ pressure gauze.

nor pressure, were quickly followed by the next step of embedding to produce the unfixed controls.

All the specimecs were dehydrated in graded ethanols and embedded in paraffin using conventional methods. Specimens were cut into $4 \mu \mathrm{m}$ sections with a microtome and used for hematoxylin-eosin stain and histochemical analysis.

Using deparaffinized $4 \mu \mathrm{m}$ sections of the kidney from each group of specimens, we conducted enzyme histochemical procedures to confirm the enzymatic activity of alkaline phosphatase (ALPase) by the lead citrate method previously reported (MAYAHARA et al., 1967).

\section{RESULTS}

All of the organs processed by hydrostatic pressure appeared paler, firmer and more elastic in comparison with the unfixed organs, somewhat resembling the formalin-fixed organs (Fig. 2). They were easily trimmed by a knife. These changes were more conspicuous in organs treated at higher pressures. However, even in the organs processed at a pressure of
$800 \mathrm{MPa}$, the changes were not as great as those seen in the formalin-fixed organs. Increasing the time to more than 15 min seemed to cause no further differences in gross appearance, whereas specimens subjected to pressure for less than 10 min appeared to be insufficiently changed.

The optimal pressure and duration were determined by numerous trials, and a pressure of 400 to $500 \mathrm{MPa}$ (approximately $450 \mathrm{MPa}$ ) for $15 \mathrm{~min}$ was found to be the most suitable at room temperature for observing specimens by light microscopy. Excessive pressure $(>600 \mathrm{MPa})$ made the nuclei pyknotic and widened the perinuclear space. Too low a pressure $(<400 \mathrm{MPa})$ could not preserve the fine structure of the specimens as indicated by the fact that, similar to the tissue without fixation, the erythrocytes were lysed by the subsequent procedures such as dehydration with ethanols.

We found that the fine structure of the tissue processed by high pressure was well preserved in the hearts and intestines (Fig. 3). In the pressure-fixed heart, the myocardium, epicardium, endocardium, and vascular system were all clearly preserved. Nuclear structures were quite well preserved. The outlines of 
cells were smooth with neither destruction nor peeling, and the cytoplasmic details were also well preserved (no abnormal vacuoles), in contrast to the situation without pressure. Myocytes were clearly demarkated from each other, unlike formalin-fixed ones. Large interfascicular spaces were not seen, these being customary artifacts caused by parenchymal shrinkage during formalin fixation or by ethanol dehydration in the case of no fixation. Staining was uniform throughout. In the pressure-treated intestines, both the nucleus and cytoplasm were well preserved. Submucosal tissue was not detached from mucosa unlike that of unfixed specimens. In summary, in the high hydrostatic pressure treated heart and intestine, cell or tissue structures were well preserved and staining was uniform throughout the tissues. They differed from formalin-fixed specimens in the absence of excessive shrinkage of interstitial tissues.

In contrast, the fine structures of livers and kidneys were not well preserved: contacts among hepatocytes were not kept and the cytoplasm was disrupted in the liver; the tubular cells in the kidney were detached from each other. However, the erythrocytes within the tissues were not lysed.
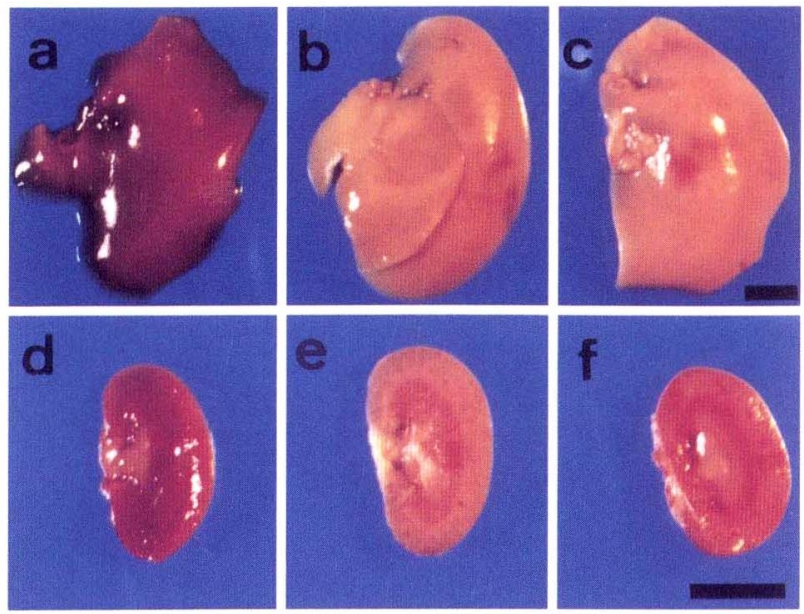

Fig. 2. Macroscopic features of livers (a-c) and coronally cut kidneys (d-f) of three mice. a and $\mathbf{d}$ : The unfixed (fresh) control, $\mathbf{b}$ and $\mathbf{e}$ : the formalin-fixed control, $\mathbf{c}$ and $\mathbf{f}$ : the hydrostatic pressure-treated group (450 MPa for $15 \mathrm{~min}$ ). There is no abnormal deformity of the high hydrostatic pressuretreated organs $(\mathbf{c}, \mathbf{f})$. They seem paler compared with the fresh organs (a, d), and are firm enough to be easily cut with a knife. Discoloration of the pressure-treated liver (c) is very conspicuous. In the kidneys, the border between the cortex and medulla is clear in each group. Bar $=5 \mathrm{~mm}$.
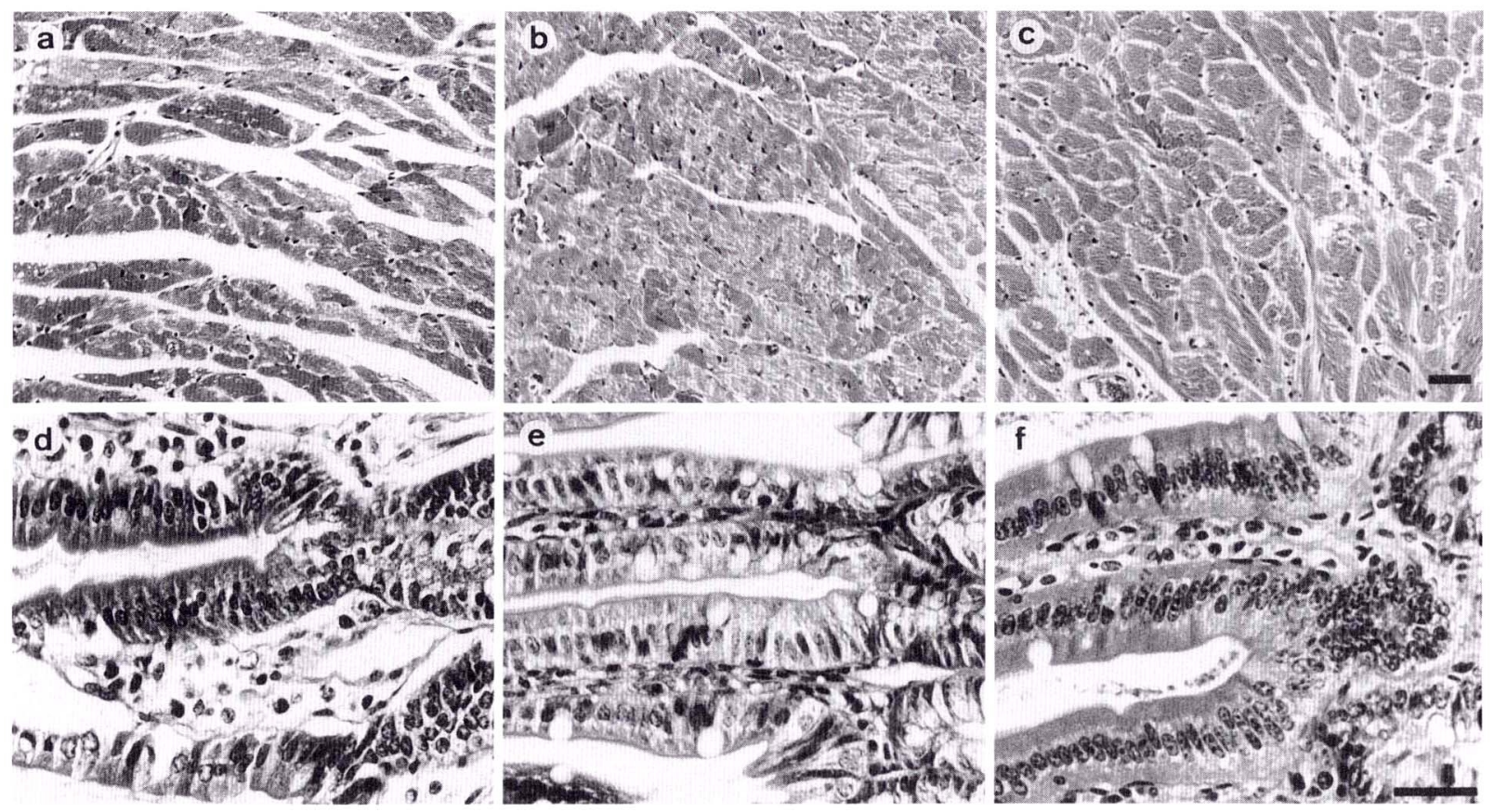

Fig. 3. Microscopic features of mouse hearts (a-c, original magnification x200) and intestines (d-f, original magnification $\times 400$ ). $\mathbf{a}$ and $\mathbf{d}$ : The organs with neither formalin nor pressure, $\mathbf{b}$ and $\mathbf{e}$ : the formalin-fixed organs, and $\mathbf{c}$ and $\mathbf{f}$ : the hydrostatic pressure-fixed organs (450 MPs for $15 \mathrm{~min}$ ). All preparations are paraffin sections with hematoxylin and eosin staining. Bar $=10 \mu \mathrm{m}$. 
a

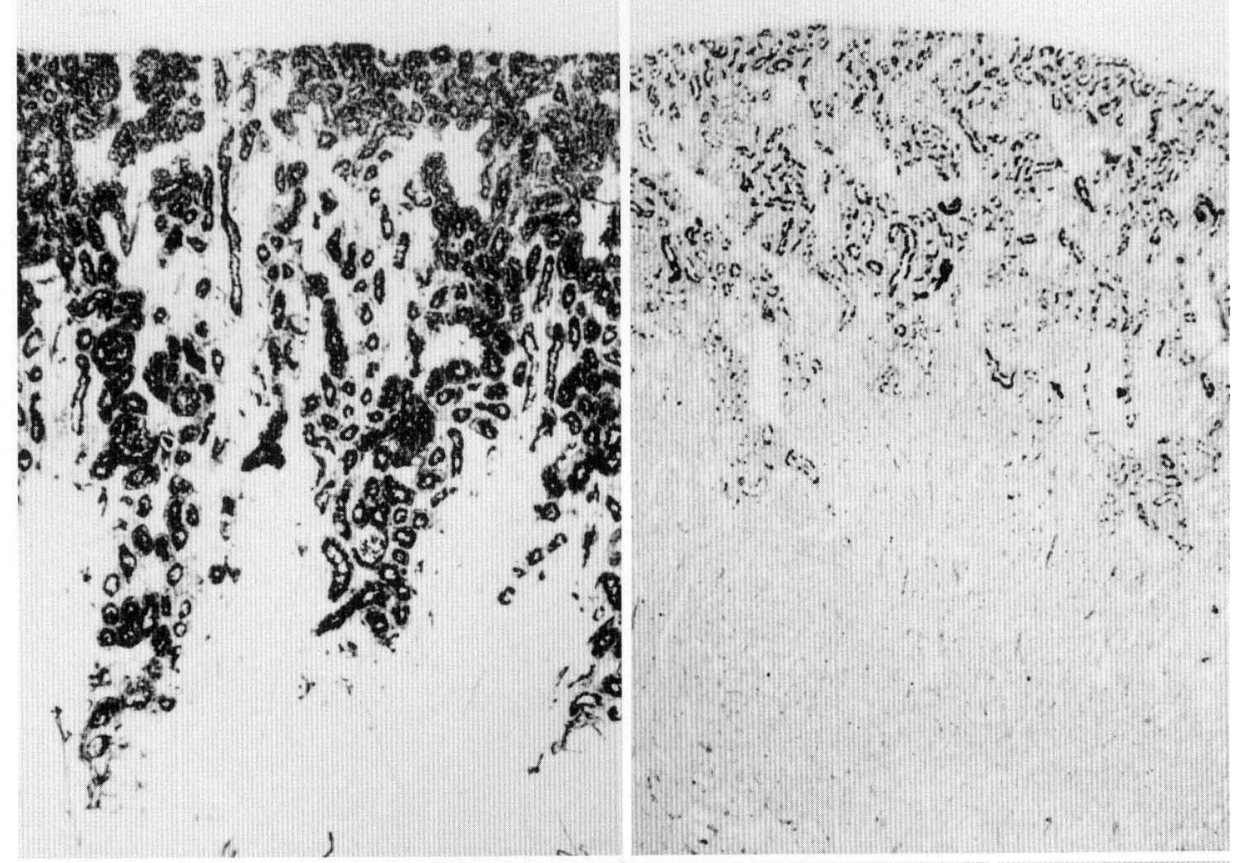

\title{
C
}

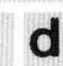

e

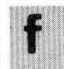

g

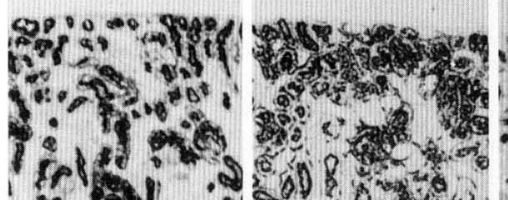

Eple

7.

Rे?

(4)

ia.
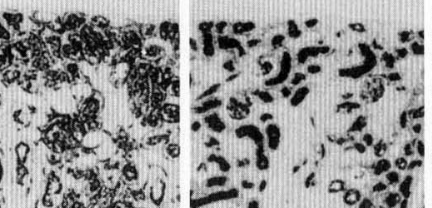

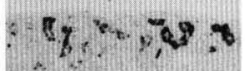
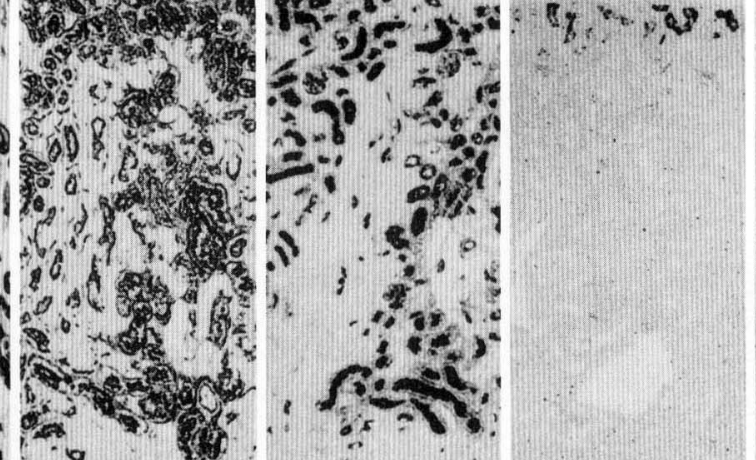

(1)

.

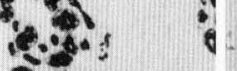

$0_{0.00}$
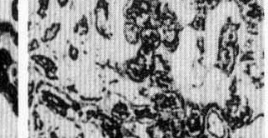

- $2 x$

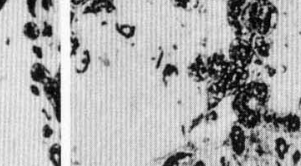

cos 
Figure 4 shows the histochemical demonstration of ALPase in each group. The enzyme activity of ALPase was seen in the brush border of the proximal convoluted tubules in the cortex. The enzyme activity was well preserved in the unfixed kidneys whereas it was markedly inactivated in the formalin-fixed kidneys. In the pressure-treated kidney specimens, the enzyme activity decreased as the pressure increased. However, it was reasonably well preserved in kidneys subjected to pressures of less than 500 $\mathrm{MPa}$, where the basic structure was also well preserved in some organs.

\section{DISCUSSION}

In the present study, we found that high hydrostatic pressure represents a potential fixative for morphologic examination of some biological specimens. Nearly three quarters of a century ago, Bridgman reported for the first time the denaturating effect on protein of hydrostatic pressure; a hydrostatic pressure of $700 \mathrm{MPa}$ coagulated the white of an egg at room temperature so that it resembled a hard-boiled egg (BRIDGMAN, 1914). Our findings are given some theoretical support by the Bridgman's report and subsequent studies (JOHNSON et al., 1954; HEREMANS, 1982) on protein denaturation by hydrostatic pressure. Denaturation due to pressure is not likely to be caused by changes of covalent bonds, but by changes of weak noncovalent bonds: an increase of hydrogen bonding, and decrease of both electrostatic forces and hydrophobic interactions at the intramolecular and intermolecular levels (JOHNSON et al., 1954; KAUZMANN, 1959; SUZUKI and SUZUKI, 1962; HeREMANS, 1982). In contrast, formalin denatures proteins by the formation of covalent bonds between specific amino acids (BAKER, 1958). Fixation by microwave heating seems to be caused by the destruction of both covalent and non-covalent bonds due to the vigorous movement of molecules (MAYERS, 1970). Thus, the mechanism of protein denaturation by high hydrostatic pressure is fundamentally different from chemical fixatives or from microwave irradiation.

The milder denaturation produced by pressure may result in a better preservation of tissue structure and more uniform staining in some organs. It may also result in less loss of tissue enzyme activity when compared with formalin fixation. Thus, we might be observing a more natural form which is closer to the original structure by the use of tissue fixed by hydrostatic pressure than when using formalin-fixed tissue.

The "unfixed" group in the present study is apparently influenced by the subsequent process of dehydra- tion (ethanol fixation) because it is well known that ethanol is one of the representatives of coagulanttype fixatives (BAKER, 1958). For all groups, the dehydration process cannot be omitted for the next embedding process. Therefore, "unfixed" is a temporal naming for the first processing of tissues. It should be noted that pressure-treated tissue was dissimilar to the unfixed control (ethanol only) despite being also exposed to ethanol. This indicates that the pressure definitely changed the tissue constituents into resistant ones against ethanol as formalin did.

The relatively short time required for processing is one of the greatest merits of this method. This method increases safety in handling because there is no risk of toxicity or carcinogenicity unlike the use of currently prevailing chemical fixatives. Also, because hydrostatic pressure is instantly transmitted to the deepest parts of a specimen in contrast to chemical fixatives which gradually permeate from the surface, every portion of a specimen is likely to be fixed equally. We believe that more advantages of hydrostatic pressure as a fixation method will be found in the future. However, the biggest problem of the present method is its organ-specificity: in contrast with the heart and intestine, the fine structures of the liver and kidney were poor. At present, we do not know the reason for this organ-specificity. The elucidation of its cause and methods for improvements are under investigation in our laboratories. One other issues that should be elucidated is whether the present method is also applicable to the subcellular level; this is under investigation in our laboratory, too.

Acknowledgements. We wish to thank Messrs. Harumasa TANABE, Koichi NagaOKa, and Katsuhiko Tsuzura (Kobe Steel, Co., Ltd., Kobe, Japan) for supplying us with the pressure apparatus and Dr. Yoshiki TAKATSU (Hyogo Prefectural Amagasaki Hospital) and Mr. Hirotsugu SuzuKa (Nippon Shin-yaku Co., Ltd.) for their cooperation and encouragement. We also thank Ms. Mika YoShiDA, Ms. Michiko Hatsuoka, Ms. Satoko Ikegaya, Ms. Keiko Tatsumi, Ms. Yukako Toba, Ms. Keiko Kagawa, Ms. Miho TOTTORI and Ms. Masako MoRitani for their technical assistance, and Ms. Yumiko Yamamoto and Ms. Ikuko HAYASH for their help in preparation of the manuscript.

\section{REFERENCES}

BAKer, J. R.: Principles of biological microtechnique. Methuen, London, 1958.

Bridgman, P. W.: The coagulation of albumen by pressure. J. Biol. Chem. 19: 511-512 (1914). 
Heremans, K.: High pressure effects on proteins and other biomolecules. Ann. Rev. Biophys. Bioeng. 11: 1-21 (1982).

Johnson, F. H., H. Eyring and M. J. Polissar: The kinetic basis of molecular biology. Wiley, New York, 1954.

KaUzmanN, W.: Some factors in the interrelation of protein denaturation. Adv. Protein Chem. 14: 1-63 (1959).

Mayahara, H., T. Saito, H. Hirano and K. Ogawa: The new lead citrate method for the ultracytochemical demonstration of activity of non-specific alkaline phosphatase (orthophoric monoester phosphohydrolase). Histochemie 11: 88-96 (1967).

Mayers, C. P.: Histological fixation by microwave heating. J. Clin. Pathol. 23: 273-275 (1970).

SuzukI, C. and K. Suzuki: The protein denaturation by high pressure. Changes of optimal rotation and susceptibility to enzymic proteolysis with ovalbumin denatured by pressure. J. Biochem. 52: 67-71 (1962)

Dr. Hisayoshi FujIWARA

The Third Division

Department of Internal Medicine Kyoto University School of Medicine 54 Kawara-cho Shogoin, Sakyo-ku Kyoto, 606 Japan

\section{藤原 久義} 606 京都市左京区聖護院川原町 54 京都大学医学部附属病院 第三内科学教室 